\section{Elastic Recovery in Capillary Flow}

Is a previous communication ${ }^{1}$ the non-Newtonian behaviour of certain visco-elastic materials, including rubber solutions and soap-thickened mineral oils, was discussed. Experiment had shown that when such liquids flow through a capillary there is a loss in pressure at the tube entrance followed by a uniform fall in pressure down the remainder of the tube. This loss was shown to be large, particularly at high stresses, and if expressed in the form of an end 'correction', sometimes amounted to as much as fifty diameters. The effect was attributed in a general way to the elastic nature of the material since it did not occur in Newtonian liquids or solid-liquid suspensions. In addition, this 'elastic end effect', as it was termed, was found to be related to the recovery or swelling of the column of liquid issuing from the capillary.

Elastic recovery normally starts at the actual capillary end, but it has now been observed that at high stresses, corresponding to velocities of one or two metres per second, recovery is delayed. The delay becomes more pronounced if velocity is in. creased further, as the accompanying photographs show. All the materials and concentrations so far studied show this phenomenon.

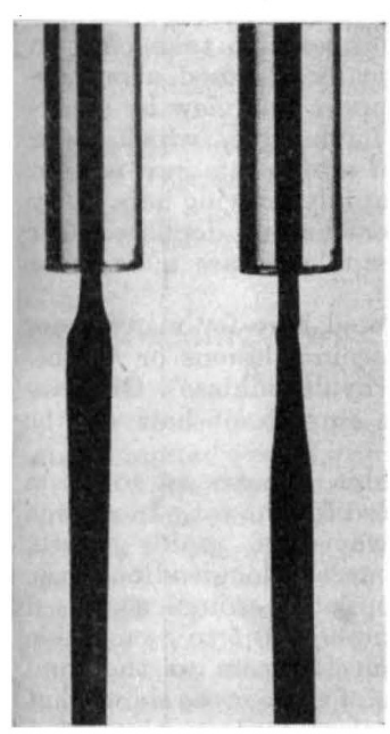

$3.7 \mathrm{~m} . / \mathrm{sec} . \quad 5.5 \mathrm{~m} . / \mathrm{sec}$ Mean velocity.

It was also found that with certain solutions the onset of this delay coincided with an unmistakable 'kink' in the flow curve, indicating a sudden increase in the rate of flow.

It is not possible at this stage to state the exact cause of these anomalies - the delay in recovery and sudden increase in the flow-rate -but several explanations are possible. It might, for example, be due to slip at the tube wall. A more likely explanation, however, involves the question of time. At low velocities recovery is very rapid compared with the downward movement; but at high velocities the liquid may not be

able to make any appreciable recovery until it has moved some distance from the tube; hence the delay in the appearance of the swelling.

With normal recovery the swelling is usually very rapid (cf. Fig. $2^{1}$ ) and it seems possible that this may react on flow immediately inside the tube, producing a small 'back pressure' tending to restrict the flow. This restriction would be removed when recovery took place well away from the capillary, and we should expect a sudden increase in the flow-rate at the transition. This idea seems to be supported by the fact that the 'kink' is apparent in precisely those materials which show a relatively large recovery (and consequently a large entrance loss) ; in cases where recovery is relatively small, no appreciable 'kink' oceurs.

6 Redford Road, Horsham,

Sussex. Dec. 29.

'Morrington, A. C., Nature, 152, 663 (1943).

\section{Internal Waves in the Sea}

I AM just reading with great interest the important and excellent work by H. U. Sverdrup, M. W. Johnson and R. H. Fleming, "The Oceans : their Physics, Chemistry and General Biology" [Prentice-Hall, Inc., New York, 1942. See p. 652 of this issue of Nature]. I should like to direct attention to a lapse which $I$ am. rather anxious to have pointed out. On page 592 the first observation of internal waves in the sea is attributed to Helland-Hansen and Nansen. The fact is that such waves were discovered in the Great Belt two years before by the nestor of Swedish oceanographers ${ }^{1}$, the late Otto Pettersson-well known as the originator of the international organization for marine researeh-and he also proved their tidal periodicity. Furthermore, on page 600 reference is incidentally made to observations of internal waves in a Swodish fjord which Otto Pettersson is said to have carried out "during 2 months of 1909". As a matter of fact, these observations were continued over several years ${ }^{2}$, and-although particular theoretical conclusions which Pettersson inferred are open to serious criticism-the observations themselves are in their method by far the most exhaustive ever made.

These comments may seem to be of minor importance, but since internal waves have, of late, attracted the intense and increasing interest of oceanographers, and since Otto Pettersson himself was from the first aware of the importance of his discovery and took particular interest in it, I think we owe him the justice of acknowledging his priority, at the same time as we recognize the important contributions of Nansen and Helland-Hansen.

Gostad, Stockaryd,

V. WALFRTD EkMaN. Göteborg.

${ }^{1}$ Pettersson, O., "Strömstudier vid Ostersiöns portar", Svenska Hydrografisk-biologiska Kommissionens Skrifter, 3 (1907). Also in "Ueber Meeresströmungen", Veröffentlichungen des Instituts für Meereskunde (Berlin, 1908).

"Pettersson, 0., "On the Occurrence of Iunar Periods in Solar Activity and the Climate of the Earth", Svenska Hydrografizkbrologiska Kommissionens Skrifter, 5 (1914).

Is making the statement on page 592, to which Prof. Ekman refers, "that the first observations of short-period variations which indicated the existence of internal waves were discussed by Helland-Hansen and Nansen (1909)", the authors have in mind the short-period variations observed during the 1893-96 voyage of the Fram. Nansen realized that they might be due to waves at the boundary between waterstrata of different density, but it was not until 1909 that he and Helland-Hansen, persuaded by their 1900-4 observations in the Norwegian Sea, were convinced of the reality of internal waves.

In the meantime, Otto Pettersson had observed the rise and fall, with tidal periodicity, of the boundary surface between the poorly saline water from the Baltic Sea and the more saline undercurrent from the Skagerrak. Helland-Hansen and Nansen did not acknowledge this contribution although they were aware of it (p. 239; 1909).

Technically, at least, Pettersson's claim for prior discovery is well-founded, but it is obvious that the question was one under wide discussion at the time, and the Norwegian oceanographers would make a strong claim. It is quite possible that Prof. Ekman's own work on 'dead water', published in the results 